\title{
Descripción y Evaluación Anatómica de Lesiones de Osteomielitis Mandibular en Alpacas (Vicugna pacos)
}

\author{
Description and Anatomical Evaluation of Lesions of Mandibular Osteomyelitis \\ in Alpacas (Vicugna pacos)
}

\author{
Danilo Pezo C..$^{1,3}$, Raúl Rosadio A. ${ }^{2}$, Alberto Manchego S. ${ }^{2}$, Francisco Franco F. ${ }^{1}$, \\ Walter Braga L. ${ }^{1}$
}

\section{Resumen}

Se describieron las lesiones anatomopatológicas de casos clínicos de osteomielitis en 21 alpacas adultas, seis tuis y tres crías, mediante estudios clínicos y anatomopatológicos, verificando el número, grado y progresión de las lesiones. Se buscaron alteraciones de la parte molar, espacio edéntulo y parte incisiva de las caras bucal y lingual del cuerpo mandibular izquierdo y derecho. En todos los casos, las lesiones se presentaron en la mandíbula, mayormente en el lado izquierdo. La osteomielitis fue predominantemente grave en las crías, donde una hiperostosis, rarefacción, necrosis, involucro y secuestro desarrolla en menor tiempo que en adultos y tuis. Las lesiones leves fueron engrosamientos focalizados en la mandíbula izquierda, mientras que las lesiones moderadas y graves fueron multifocales en ambos lados, con la presencia de ulceraciones y fístulas directamente relacionadas con la progresión de las lesiones.

Palabras clave: alpaca, osteomielitis, maxilar inferior, inflamación

\section{AbSTRaCT}

The anatomopathological lesions of clinical cases of osteomyelitis in 21 adult alpacas, six tuis and three baby alpacas were described through clinical and pathological evaluation, determining the number, degree, and progression of the lesions. Alterations of the molar part, edentulous space, and incisive part of the buccal and lingual sides of the left and right mandibular body were observed. In all cases, the lesions appeared in the mandible, mostly on the left side. Osteomyelitis was predominantly severe in the youngest

\footnotetext{
${ }^{1}$ Estación Experimental Marangani del Centro de Investigación IVITA, Facultad de Medicina Veterinaria, Universidad Nacional Mayor de San Marcos, Cusco, Perú

${ }^{2}$ Laboratorio de Microbiología y Parasitología Veterinaria, Facultad de Medicina Veterinaria, Universidad Nacional Mayor de San Marcos, Lima, Perú

${ }^{3}$ E-mail: dpezo71@hotmail.com
}

Recibido: 3 de enero de 2017

Aceptado para publicación: 12 de junio de 2017 
alpacas, where hyperostosis, rarefaction, necrosis, involvement, and sequestration develops in less time than in adults and tuis. Mild lesions were thickened in the left mandible, while moderate and severe lesions were multifocal on both sides, with ulcerations and fistulas directly related to the progression of lesions.

Key words: alpaca, osteomyelitis, lower mandible, inflammation

\section{INTRODUCCIÓN}

La osteomielitis mandibular en alpacas es una enfermedad endémica que afecta a animales de diferente edad, raza y sexo. La osteomielitis ocasiona severas pérdidas económicas a los pequeños productores alpaqueros debido a la pobre producción de fibra y condición corporal y, en consecuencia, por la saca de animales de alto valor genético (Cuba, 1949; Moro, 1956; Franco et al., 1998; Ramírez, 1998). La enfermedad tiene amplia distribución, escasa respuesta al tratamiento, morbilidad elevada y altos costos para el sistema sanitario (Acha y Szyfres, 2001; Calhoun et al., 2009; Pezo et al., 2014), se presenta esporádicamente y se desconoce la incidencia y prevalencia de esta enfermedad a nivel de productor, ya que no se llevan registros de mortalidad y morbilidad. La información de centros experimentales nacionales indica prevalencias de 2.9, $5.9 \mathrm{y}$ $18.4 \%$ en crías, tuis y adultos, respectivamente (Ramírez, 1991).

La osteomielitis en alpacas ha sido descrita como una inflamación ósea ocasionada generalmente por agentes septicémicos como Actinomyces, Streptococcus, Fusobacterium, Corynebacterium pyogenes y Staphylococcus spp (Moro, 1956; Lovón, 1995). Se desconocen los posibles mecanismos patogénicos de las bacterias osteotrópicas (Blood y Radostits, 1986), que al parecer aprovechan las lesiones locales para iniciar su adherencia, penetración tisular y activar propiedades osteolíticas y osteogénicas (Jubb et al., 1993). Cuba (1949) examinó 542 alpacas encontrando lesiones en la mandíbula en 43 animales, donde 17 mostraban tumoraciones submandibulares con ulceraciones, ocho con lesiones submandibulares sin ulceración, y 15 con engrosamientos en al menos una de las ramas de la mandíbula; lesiones que se consideraron como inicio de la enfermedad.

El proceso de la osteomielitis clínica empieza con un abultamiento leve de la mandíbula, que progresa con el tiempo, pudiendo llegar a producirse la fractura del hueso. En los casos iniciales se observa que la lesión se localiza en el canal del agujero nutricio, notándose solamente una proliferación de tejido óseo y fibroso. En los casos más avanzados, la fistula comunica con la cavidad bucal, del cual fluye secreción purulenta. Al interior de la mandíbula se observan pequeñas cavidades cubiertas de tejido fibroso enrojecido que prolifera y al corte de estas cavidades se observa secreción purulenta (Cuba, 1949; Moro, 1956; Pezo et al., 1996).

En el presente estudio se evaluó la osteomielitis mandibular en alpacas, mediante estudios clínicos, con el objetivo de describir las lesiones de esta enfermedad.

\section{Materiales y Métodos}

El procesamiento de los casos clínicos y análisis de las muestras se realizó en la Estación Experimental Maranganí, del Instituto Veterinario de Investigaciones Tropicales y de Altura (IVITA), ubicado en el distrito de Maranganí, región Cusco, a 4313 msnm. 
Se trabajó con 30 alpacas Huacaya con procesos de osteomielitis clínica entre 2012 y 2014. De estas, 21 eran alpacas adultas ( $>3$ años), 6 tuis (1-2 años) y 3 crías ( 1 mes), pertenecientes al Centro Experimental la Raya-UNSAAC, Cusco. Los animales fueron sacrificados bajo las normas del Comité de Ética y Bienestar Animal (CEBA) de la FMV-UNMSM.

Las lesiones macroscópicas de la parte molar del cuerpo mandibular izquierdo y derecho, espacios edéntulos en sus caras bucal y lingual y en la parte incisiva son descritas. Para una mejor descripción de las lesiones, el cuerpo mandibular fue dividido en tres partes: incisiva, edéntulo y molar, con sus respectivas caras labial, bucal o lingual (Sato y Angulo, 2015). Las lesiones por presencia de trayectos fistulosos purulentos, hiperostosis, rarefacción, necrosis e involucro con secuestro fueron diagnosticados visualmente y por palpación.

El análisis de los estudios clínicos y anatomopatológicos fueron de tipo descriptivo de acuerdo al número de presentaciones de las lesiones, grado y evolución en las ramas horizontales, espacios intermandibulares y sínfisis mandibular.

\section{Resultados}

\section{Estudios Clínicos}

En los cuadros 1 y 2 se observa el número de lesiones, según localización, tipo y grado en 21 alpacas adultas y 6 alpacas tuis, respectivamente. Las lesiones se encuentraron en la parte molar, espacio edéntulo y parte incisiva de las caras bucal y lingual del cuerpo mandibular izquierdo y derecho.

Observaciones clínicas en 21 alpacas adultas

Se observaron lesiones de grado leve $(n=3)$, moderado $(n=10)$ y grave $(n=8)$. Las lesiones leves fueron focalizadas en alpacas de buena condición corporal (CC) (Cuadro 1). Dos alpacas presentaron engrosamiento de la cara bucal de la parte molar izquierda y en la tercera alpaca se observó engrosamiento en la cara labial del espacio edéntulo que se extendía hasta la parte incisiva (Figura 1A).

Las 10 alpacas con osteomielitis moderada tenían CC regular y lesiones consistentes en engrosamientos y tumoraciones con secreciones purulentas adheridas a la fibra de la zona submandibular, en donde se observó la presencia de una fístula (Figura 1B). En tres animales se encontró la abertura interna de la fístula en la cavidad bucal conteniendo pasto, restos del bolo alimenticio y secreciones purulentas que drenaban al exterior. Siete animales presentaron abultamientos y tumoraciones multifocales en la cara labial y lingual del cuerpo mandibular izquierdo. En dos alpacas se palparon engrosamientos y tumoraciones en el espacio edéntulo y en uno de ellos la lesión continuaba hasta la parte incisiva. En un animal el engrosamiento continuaba hasta el espacio edéntulo derecho, donde las lesiones eran más leves. Una alpaca solo presentó engrosamiento y tumoración en la parte incisiva (Cuadro 1).

Las ocho alpacas con lesiones graves presentaban evidente pérdida de peso y dificultad para alimentarse y caminar. En cinco casos, se observó una ligera desviación de la mandíbula al lado opuesto de la lesión (Figura 1C). Se observaron secreciones purulentas adheridas a la fibra, engrosamientos y tumoraciones a nivel submandibular, que a la palpación, abarcaban el cuerpo mandibular izquierdo, el espacio edéntulo en sus caras labial y lingual, parte incisiva continuando al espacio edéntulo, y finalmente el cuerpo mandibular derecho. Las lesiones fueron más severas y frecuentes en el lado izquierdo (Cuadro 1). Además, en tres alpacas se observaron fístulas en el interior de la boca con abundante material purulento y pequeños pedazos de secuestros entremezclados con pasto, que drenaban el exterior (Figuras 1D, 1E, 1F). 
Cuadro 1. Número de lesiones (N. $\left.{ }^{\circ}\right)$ según localización, tipo y grado en 21 alpacas adultas con osteomielitis de la parte molar, espacio edéntulo y parte incisiva de las caras bucal y lingual del cuerpo mandibular izquierdo y derecho

\begin{tabular}{|c|c|c|c|c|c|c|c|}
\hline \multirow[b]{2}{*}{ Localización } & \multirow[b]{2}{*}{ N. ${ }^{\circ}$} & \multicolumn{3}{|c|}{ Tipo de lesión } & \multicolumn{3}{|c|}{ Grado } \\
\hline & & 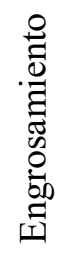 & 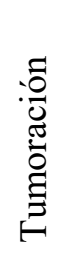 & 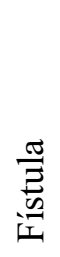 & 苞 & 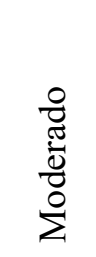 & $\underset{\overparen{J}}{己}$ \\
\hline Cuerpo mandibular izquierdo cara bucal & 37 & 14 & 11 & 12 & 2 & 20 & 15 \\
\hline Cuerpo mandibular izquierdo cara lingual & 16 & 8 & 8 & - & - & 8 & 8 \\
\hline Espacio edéntulo izquierdo cara bucal & 30 & 11 & 9 & 10 & 1 & 5 & 24 \\
\hline Espacio edéntulo izquierdo cara lingual & 14 & 7 & 7 & - & - & & 14 \\
\hline Parte incisiva & 29 & 12 & 11 & 6 & 1 & 7 & 21 \\
\hline Cuerpo mandibular derecho cara bucal & 11 & 8 & 3 & - & - & 2 & 9 \\
\hline Cuerpo mandibular derecho cara lingual & 7 & 5 & 2 & - & - & 2 & 5 \\
\hline Espacio edéntulo derecho cara bucal & 23 & 9 & 8 & 6 & - & 3 & 20 \\
\hline Espacio edéntulo derecho cara lingual & 10 & 7 & 3 & - & - & 1 & 9 \\
\hline Total & 177 & 81 & 62 & 34 & 4 & 48 & 125 \\
\hline
\end{tabular}

Observaciones clínicas de osteomielitis en seis tuis

En cuatro alpacas tuis con buena CC se observaron lesiones leves de osteomielitis (Cuadro 2). En otras dos, con bajo peso y $\mathrm{CC}$ regular, se observaron lesiones moderadas con secreciones purulentas adheridas a la fibra de la zona submandibular. A la palpación se apreció un marcado engrosamiento y tumoración en la cara lingual de la parte molar del cuerpo mandibular inferior izquierdo. Además, se observó la presencia de fístulas a nivel submandibular en la parte molar del cuerpo mandibular inferior izquierdo y en la parte incisiva. Las fístulas comunicaban desde el interior de la boca con el hueso mandibular y, a su vez, con el exterior drenando pus (Cuadro 2).
Observaciones clínicas de osteomielitis en tres crías

Tres crías, entre 20 y 45 días de edad, con escaso desarrollo, decaimiento y depresión, presentaron lesiones graves. Se encontraron fístulas internas entre la base de los premolares y molares con material purulento entremezclado con pasto. En dos animales se observó a la palpación engrosamiento y tumoración en la parte molar del cuerpo mandibular inferior derecho (Figura $1 \mathrm{G}$ ) y en el otro, en la parte molar del cuerpo mandibular inferior izquierdo. Estas crías murieron durante el desarrollo de la enfermedad.

\section{Estudios Patológicos}

En los Cuadros 3 y 4 se presenta el número de lesiones macroscópicas y su evolu- 
Cuadro 2. Número de lesiones $\left(\mathrm{N}^{\circ}{ }^{\circ}\right)$ según localización, tipo y grado en 6 alpacas tuis con osteomielitis de la parte molar, espacio edéntulo y parte incisiva de las caras bucal y lingual del cuerpo mandibular izquierdo y derecho

\begin{tabular}{|c|c|c|c|c|c|c|c|}
\hline \multirow[b]{2}{*}{ Localización } & \multirow[b]{2}{*}{ N. ${ }^{\circ}$} & \multicolumn{3}{|c|}{ Tipo de lesión } & \multicolumn{3}{|c|}{ Grado } \\
\hline & & 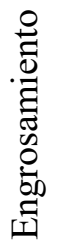 & 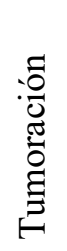 & 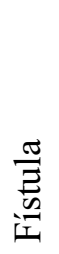 & 岂 & 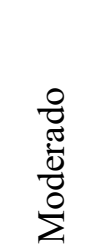 & 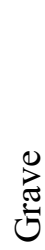 \\
\hline Parte molar izquierdo cara bucal & 4 & 2 & 1 & 1 & 1 & 1 & 2 \\
\hline Parte molar izquierdo cara lingual & 6 & 3 & 3 & - & 4 & 2 & - \\
\hline Espacio edéntulo izquierdo cara bucal & 0 & - & - & - & - & - & - \\
\hline Espacio edéntulo izquierdo cara lingual & 0 & - & - & - & - & - & - \\
\hline Parte incisiva & 3 & 1 & 1 & 1 & & 3 & - \\
\hline Parte molar derecho cara bucal & 5 & 3 & 2 & - & 1 & - & 4 \\
\hline Total & 18 & 9 & 7 & 2 & 6 & 6 & 6 \\
\hline
\end{tabular}

Cuadro 3. Número de lesiones (n) macroscópicas y su evolución en 21 alpacas adultas con osteomielitis de la parte molar, espacio edéntulo y parte incisiva de las caras bucal y lingual del cuerpo mandibular izquierdo y derecho

\begin{tabular}{|c|c|c|c|c|c|c|c|c|c|}
\hline \multirow[b]{2}{*}{ Localización } & \multirow[b]{2}{*}{$\mathrm{n}$} & \multicolumn{5}{|c|}{ Tipo de lesión } & \multicolumn{3}{|c|}{ Evolución } \\
\hline & & 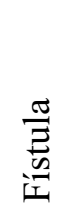 & $\begin{array}{l}\cdot \frac{n}{\omega} \\
0 \\
0 \\
0 \\
0 \\
0 \\
0 \\
0\end{array}$ & 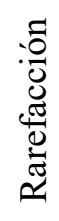 & 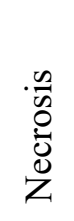 & 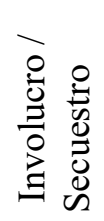 & $\begin{array}{l}\frac{8}{0} \\
\underset{20}{20}\end{array}$ & 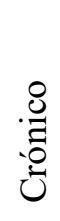 & 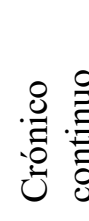 \\
\hline Parte molar izquierdo cara bucal & 51 & 12 & 14 & 10 & 10 & 5 & 2 & 24 & 25 \\
\hline Parte molar izq cara lingual & 29 & 4 & 9 & 8 & 8 & - & 1 & 12 & 16 \\
\hline Espacio edéntulo izq cara bucal & 43 & 10 & 11 & 9 & 7 & 6 & 1 & 8 & 34 \\
\hline Espacio edéntulo izq cara lingual & 23 & - & 6 & 6 & 6 & 5 & - & - & 23 \\
\hline Parte incisiva & 38 & 6 & 12 & 10 & 6 & 4 & 1 & 8 & 29 \\
\hline Parte molar derecho cara bucal & 18 & 2 & 8 & 3 & 3 & 2 & - & 2 & 16 \\
\hline Parte molar derecho cara lingual & 11 & - & 5 & 2 & 2 & 2 & - & 2 & 9 \\
\hline Espacio edéntulo der cara bucal & 31 & 6 & 9 & 7 & 5 & 4 & - & 3 & 28 \\
\hline Espacio edéntulo der cara lingual & 15 & 4 & 5 & 2 & 2 & 2 & - & 1 & 14 \\
\hline Total & 259 & 44 & 79 & 57 & 49 & 30 & 5 & 60 & 194 \\
\hline
\end{tabular}



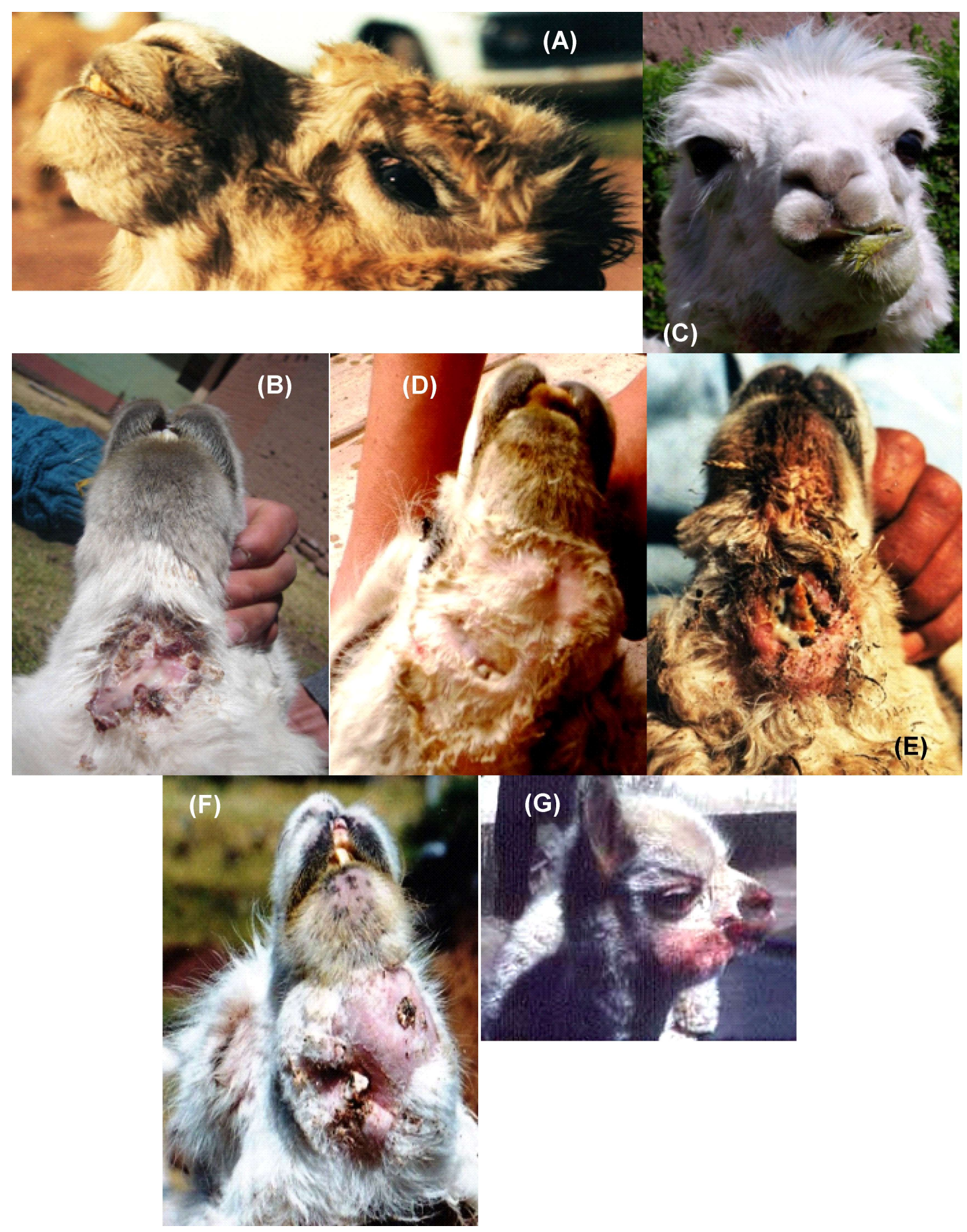

Figura 1. Lesiones macroscópicas en alpacas con osteomielitis. A: Lesión de grado leve en la parte incisiva de una alpaca adulta. B: Lesión fistulada moderada submandibular. C: Desviación de la mandíbula. D: Fístula purulenta grave submandibular. E: Secuestros en fístula submandibular. E: Fístulas, engrosamiento y tumoraciones submandibular graves. G: Cría con engrosamiento y tumoración mandibular derecha 


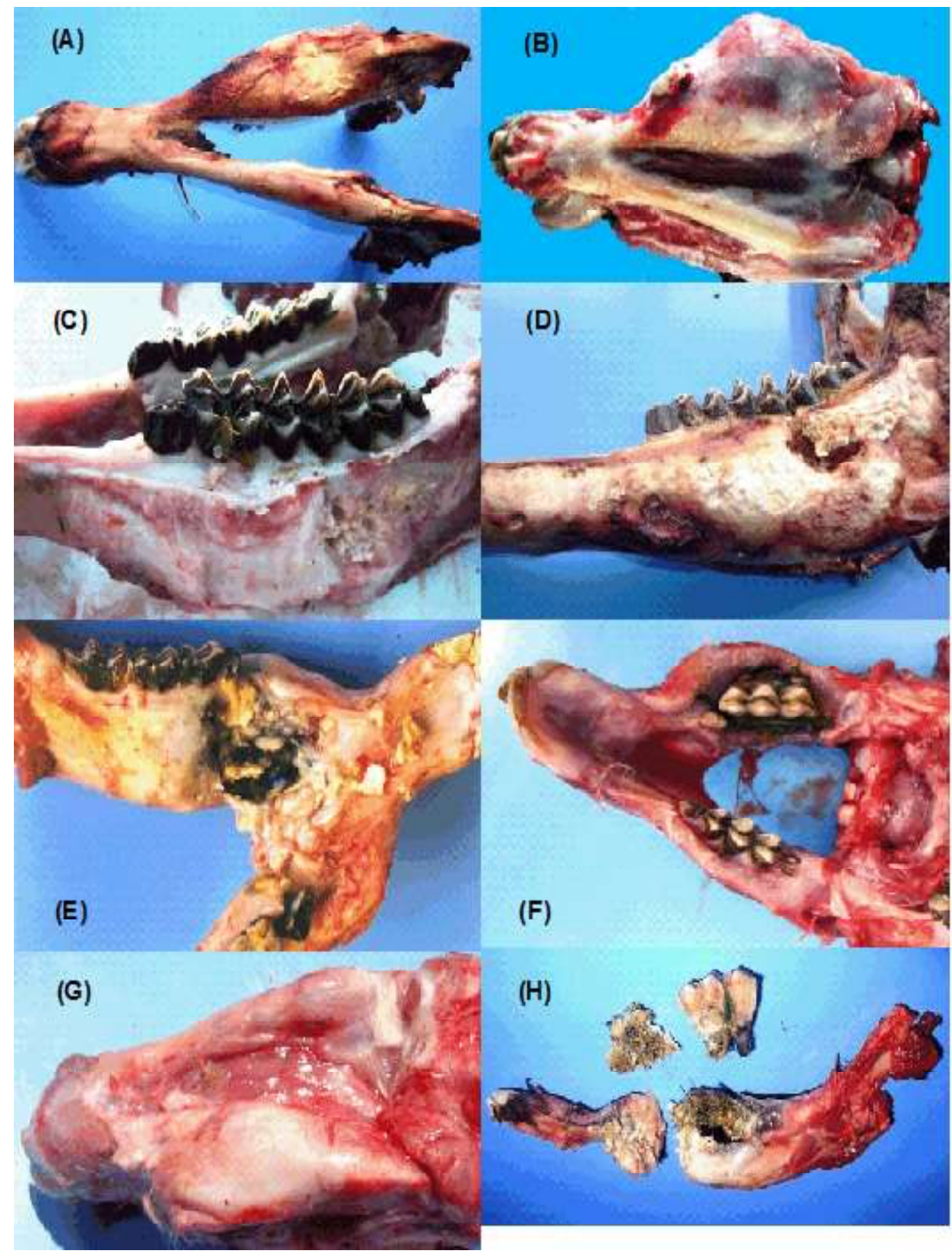

Figura 2. Lesiones macroscópicas óseas en alpacas con osteomielitis. A: Hiperostosis en la cara lingual y labial del cuerpo mandibular inferior izquierdo de una alpaca adulta. B: Lesión crónica con trayecto fistuloso purulento e hiperostosis de la mandíbula izquierda (vista ventral) de una alpaca adulta. C: Lesión crónica en alpaca adulta, hiperostosis, rarefacción y necrosis en la cara bucal y lingual de la mandíbula izquierda (vista lateral). D: Hiperostosis y rarefacción ósea de la mandíbula izquierda de una alpaca adulta. E: Necrosis, secuestros, disolución ósea y fractura de la mandíbula de una alpaca adulta. F: Hiperostosis submandibular en una cría. G: Neoformación de tejido óseo en una cría. H: Piezas dentales rechazadas, porción basal descubierta e involucro con secuestros óseos y exudado purulento 
Cuadro 4. Número de lesiones (n) macroscópicas y su evolución en seis alpacas tuis con osteomielitis de la parte molar del cuerpo mandibular, caras bucal y lingual, del mandibular izquierdo y derecho y parte incisiva

\begin{tabular}{|c|c|c|c|c|c|c|c|}
\hline \multirow[b]{2}{*}{ Localización } & \multirow[b]{2}{*}{$\mathrm{n}$} & \multicolumn{4}{|c|}{ Tipo de lesión } & \multicolumn{2}{|c|}{ Evolución } \\
\hline & & 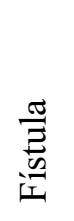 & $\begin{array}{l}\frac{n}{n} \\
0 \\
0 \\
0 \\
0 \\
0 \\
0 \\
0\end{array}$ & 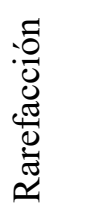 & 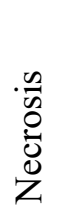 & $\underset{8}{\stackrel{8}{8}}$ & 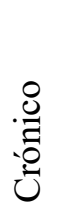 \\
\hline Parte molar izquierdo cara bucal & 2 & 1 & 1 & - & - & 1 & 1 \\
\hline Parte molar izquierdo cara lingual & 7 & - & 3 & 3 & 1 & 4 & 3 \\
\hline Parte incisiva & 4 & 1 & 1 & 1 & 1 & - & 4 \\
\hline Parte molar derecho cara bucal & 1 & - & 1 & - & - & 1 & - \\
\hline Total & 14 & 2 & 6 & 4 & 2 & 6 & 8 \\
\hline
\end{tabular}

ción en 21 alpacas adultas y 6 tuis, respectivamente, con osteomielitis mandibular de la parte molar, espacio edéntulo y parte incisiva de las caras bucal y lingual del cuerpo mandibular izquierdo y derecho.

Lesiones macroscópicas en 21 alpacas adultas

Tres alpacas presentaban lesiones agudas iniciales, caracterizadas por prominencias hiperostósicas en la base de los dientes premolar y molar (Cuadro 3). Un animal evidenció lesiones en las caras bucal y lingual del cuerpo mandibular inferior izquierdo (Figura 2A). Un segundo animal desarrolló hiperostosis solo en la cara bucal del mandibular izquierdo, mientras que el tercer animal mostró únicamente una hiperostosis extendida desde del espacio edéntulo izquierdo hasta la parte incisiva.

Diez alpacas presentaron lesiones crónicas caracterizadas por tumoraciones con prominencia en la región submandibular, en la base de los dientes premolares y molares. En todos los casos se observaron amplias cavidades con exudado purulento cremoso verdoso, pasto y desechos que se alternaban con rarefacción del tejido óseo, donde el proceso inflamatorio que afectaba al hueso se extendía hasta las partes blandas, mediante trayectos fistulosos purulentos que se abren a la piel (Figura 2B). En siete de estos animales se observó hiperostosis, rarefacción y necrosis en la cara bucal y lingual de la parte molar de la mandíbula izquierda (Figura 2C). Dos alpacas presentaron hiperostosis, rarefacción y necrosis en el espacio edéntulo, donde las lesiones en una de ellas continuaban hasta la parte incisiva, mientras que en el otro animal continuaban hasta el espacio edéntulo derecho, donde la hiperostosis era menos evidente. En la décima alpaca solo se encontró hiperostosis en la parte incisiva (Cuadro 3).

Ocho alpacas evidenciaron un proceso inflamatorio crónico continuo que afectó la cara bucal y lingual de la parte molar del cuerpo mandibular izquierdo y derecho, edéntulo y parte incisiva, siendo más graves y frecuentes en el cuerpo mandibular izquierdo (Cuadro 4). Las lesiones se extendieron a las par- 
tes blandas formando trayectos fistulosos purulentos que se abrieron en la piel. En el interior de la boca, los trayectos fistulosos comunicaban la cavidad bucal con la lesión ósea, la cual contenía material purulento entremezclado con pasto. Además de las lesiones de hiperostosis, rarefacción y necrosis, se pudo observar involucro con secuestros, disolución ósea y fractura de la mandíbula. Los alvéolos dentarios presentaron obliteración total o parcial, con presencia de tejido óseo de aspecto osteolítico, pérdida de la estructura de las paredes interalveolares e inflamación con pérdida de las paredes de los alvéolos dentarios (Figura 2D, 2E).

\section{Lesiones macroscópicas en seis tuis}

A la necropsia, todos presentaron hiperostosis aguda focalizada sin afectar la base de los dientes molares. Tres de estos animales mostraron hiperostosis de la mandíbula izquierda en la cara bucal $(\mathrm{n}=1)$ y lingual $(n=2)$, respectivamente. En dos de ellos, la hiperostosis incluyó rarefacción de la cara lingual de la mandíbula izquierda. Solo un tui evidenció hiperostosis en la mandíbula derecha en la cara bucal. En dos tuis se observaron formaciones fistulosas purulentas a nivel submandibular en el cuerpo mandibular izquierdo y en la sínfisis mandibular. Las fístulas comunicaban desde la cavidad bucal hasta el hueso, y contenían material purulento entremezclado con pasto que drenaban al exterior. Además, en uno se halló hiperostosis, rarefacción y necrosis en la cara lingual del cuerpo mandibular izquierdo. Otro tui también presentó, además, hiperostosis, rarefacción y necrosis en la sínfisis mandibular (Cuadro 4).

\section{Lesiones macroscópicas en tres crías}

A la necropsia, en dos crías se observaron lesiones de hiperostosis de la mandíbula derecha con prominencia en la región submandibular y en la otra cría en la mandíbula izquierda (Figura 2F). Las lesiones ocu- rrían con rarefacción, necrosis e involucro con secuestro, alternadas con áreas de neoformación de tejido óseo, lo cual aumentaba notablemente el grosor de la parte molar de los cuerpos mandibulares (Figura 2H).

En una cría, las piezas dentales estaban rechazadas hacia arriba y dejaban descubierta la porción basal de las raíces dentarias, donde se observaron amplias cavidades (involucro) que contenían secuestros óseos llenas de exudado purulento (Figura $2 \mathrm{H}$ ). La osteomielitis crónica se extendió a las partes blandas a través de formaciones fistulosas purulentas desde la cavidad bucal hasta la lesión ósea, observándose material purulento entremezclado con pasto entre la base de los premolares y los molares.

\section{Discusión}

En todos los casos se hallaron lesiones de osteomielitis exclusivamente en la mandíbula y con mayor frecuencia en el lado izquierdo. Las lesiones leves fueron solamente engrosamientos focalizados, mientras que las lesiones moderadas y graves fueron multifocales con la presencia de ulceraciones y fístulas, directamente relacionadas a la gravedad de la lesión.

Clínicamente se encontró que las lesiones leves eran menos frecuentes en alpacas adultas (3/21) que en tuis (4/6), y mayormente en las caras bucal o labial del cuerpo mandibular izquierdo, excepto en un tui donde la lesión estaba en la cara labial del cuerpo mandibular derecho (Cuadros 1 y 2). Según los resultados, la lesión se inicia mayormente en el lado izquierdo de la mandíbula, avanzando hacia las áreas contiguas, llegando por extensión al lado derecho. Diversos autores indican que las infecciones periodontales se originarían en los espacios interalveolares de la mandíbula, agravándose con el tiempo (Vadillo et al., 2002; Clerc et al., 2004; Niehaus, 2009). 
Los pastos de la zona, de naturaleza dura y fibrosa, con espigas barbadas, lesionan fácilmente los tejidos bucales, afectando la pérdida de continuidad del tejido sano y causando una necrosis primaria, lo cual es esencial para el ingreso y desarrollo de gérmenes saprófitos o patógenos (Cuba, 1949; Moro, 1956; Pezo et al., 1996; Fernández y Rosadio, 1998). Sin embargo, esto no explica la mayor incidencia de osteomielitis en la mandíbula izquierda; aunque se podría considerar la mayor incidencia en el lado izquierdo debido al movimiento masticatorio de los rumiantes, donde los pastos duros son mayormente prensados contra los molares de derecha a izquierda (Cuba, 1949).

El flujo de sangre durante el establecimiento de la osteomielitis aguda, crónica y secundaria en la mandíbula es fundamental para explicar el desarrollo de la enfermedad. Luego de una lesión inicial, las bacterias patógenas se dirigen por los vasos sanguíneos donde se adhieren y reproducen causando una inflamación aguda (Baltensperger y Eyrich, 2009; Calhoun et al. 2009; Mustafá et al., 2014). Entonces, a causa de trombosis vasculares o de reflejos vegetativos simpáticos y parasimpáticos, se produce una vasoconstricción de los vasos mandibulares de tipo terminal, lo cual da origen y facilita la aparición de necrosis y secuestros mandibulares (Rodríguez, 2000). Estos mecanismos descritos en humanos, probablemente ocurran en alpacas debido a que la anatomía de la mandíbula presenta también una vascularización capilar yuxtaterminal (Cuba, 1949).

Una vez iniciada la enfermedad, ya sea vía hematógena o causada por una extensión local de una infección vecina, el proceso continúa con la invasión bacteriana profunda de la médula del hueso, lo que resulta en la acumulación de detritos y exudados inflamatorios. Este acúmulo incrementa la presión y reduce aún más el flujo sanguíneo capilar, ocasionando obstrucción y necrosis. La presión del exudado medular hace que este sea empujado a través de los conductos de Havers ha- cia los canales de Volkman, alcanzando la corteza ósea (Rodríguez, 2000; Aguado, 2002).

El engrosamiento y tumoración se observó con mayor frecuencia como una hiperostosis severa caracterizada por necrosis liquefactiva con disgregación de tejido óseo y circundados por tejido conectivo fibroso neoformado. La osteítis rarefaciente fue predominante y seguida de necrosis e involucro con secuestro (Cuadros 3 y 4). Estas lesiones ocurren en los espacios medulares de la zona esponjosa e involucra a las trabéculas, observándose macroscópicamente zonas necróticas en la corteza y periostio en este estudio. Histológicamente, la osteomielitis de la mandíbula se define como una enfermedad infecciosa supurativa del hueso, la cual puede ser hematógena o causada por una extensión local infecciosa vecina (Baltensperger y Eyrich, 2009).

\section{Conclusiones}

La osteomielitis evaluada en 21 alpacas adultas, tuis y crías se presenta con lesiones óseas de diverso grado y evolución exclusiva en mandíbula, mayormente en el lado izquierdo.

- La osteomielitis fue predominantemente grave en las crías, donde la hiperostosis, rarefacción, necrosis, involucro y secuestro desarrolla en menor tiempo que en adultos y tuis.

Las lesiones leves fueron engrosamientos focalizados en la mandíbula izquierda, mientras que las lesiones moderadas y graves fueron multifocales en ambos lados, con la presencia de ulceraciones y fístulas directamente relacionadas con la progresión de las lesiones.

\section{Literatura Citada}

1. Acha PN, Szyfres B. 2001. Zoonosis y enfermedades transmisibles comunes al- 
hombre y a los animales. Vol I. Bacteriosis y micosis. $3^{\mathrm{a}}$ ed. USA: Organización Panamericana de la Salud. 398 p.

2. Aguado JM. 2002. Osteomielitis. Medicine 8(84): 4525-4528.

3. Baltensperger M, Eyrich KG. 2009. Osteomyelitis of the jaws. Berlin: Springer Berlin Heidelberg. $315 \mathrm{p}$.

4. Blood J, Radostits D. 1986. Medicina veterinaria. $7^{\circ}$ ed. México: Interamericana. $1441 \mathrm{p}$.

5. Calhoun JH, Manring, MM, Shirtliff M. 2009. Osteomyelitis of the long bones. Semin Plast Surg 23: 59-72. doi: 10.1055/s-0029-1214158

6. Clerc K, Cordero F, Saldivia CM, Vásquez LA, García ML. 2004. Abscesos faciales producidos por Actinomyces pyogenes (Arcanobacterium pyogenes) en un toro Senepol. Rev Fac Cs Vet UCV 45(1): 1-8.

7. Cuba. A. 1949. Osteomielitis del maxilar inferior en alpacas. Rev Fac Med Vet Lima 4: 25-48.

8. Fernández M, Rosadio R. 1998. Osteomielitis vertebral en alpacas. Rev Inv Pec IVITA 2: 54-58.

9. Franco E, Pezo D, García W. 1998. Gestión de centros de producción de reproductores de alpacas y llamas. Pub Tec FMV No $37.32 \mathrm{p}$.

10. Lovón E. 1995. Contribución al estudio de las enfermedades infecciosas de las alpacas, gérmenes aislados de abscesos y osteomielitis de la mandibular. Tesis de Bachiller. Lima: Univ Nacional Mayor de San Marcos. 22 p.

11. Maxie G. 2016. Jubb, Kennedy \& Palmer's pathology of domestic animals. $6^{\text {th }}$ ed. USA: Saunders. $912 \mathrm{p}$.

12. Moro M, Guerrero C. 1971. La alpaca. Enfermedades infecciosas y parasitarias. Bol Div N. ${ }^{\circ} 8$ IVITA. 63 p.

13. Moro M. 1956. Contribución al estudio de las enfermedades de los auquénidos: osteomielitis del maxilar inferior de las alpacas. Rev Med Vet Lima 8: 62-80.

14. Mustafá M, Yusof S, Iftikhar M. 2014. Osteomyelitis: pathogenesis, clinical and therapeutic challenge. Int J Med Pharma Sci 4: 9-18.

15. Niehaus A. 2009. Dental disease in 1lamas and alpacas. Vet Clin North Am Food Anim Pract 25: 281-93. doi: 10.1016/j.cvfa.2009.03.007

16. Pezo D, Franco E, Franco F, Alarcón V. 2014. Sanidad en camélidos. En: Manual del alpaquero. $2^{\mathrm{a}}$ ed. Perú. Soluciones Prácticas. p 12-45.

17. Pezo D, García W, Franco E. 1996. Examen anátomo patológico de la osteomielitis en alpacas. En: XIX Reunión de la Asociación Peruana de Producción Animal. Cusco, Perú.

18. Ramírez A, Franco E, Pezo D, García $W .1998$. Diagnóstico y control de enfermedades en camélidos sudamericanos. Pub Tec FMV No 34. 88 p.

19. Ramírez A. 1991. Enfermedades infecciosas. En: Fernández Baca $\mathrm{S}$ (ed). Avances y perspectivas del conocimiento de los camélidos sudamericanos. Ed. Santiago de Chile: Oficina Regional de la FAO para América Latina y el Caribe. p 263-323.

20. Rodríguez OL. 2000. Osteomielitis. Tesis de Especialista. Cuba: Filial Universitaria Este de La Habana. 15 p.

21. Sato A, Angulo J. 2015. Atlas de osteología de la alpaca adulta. Perú. Lima: Univ Nacional Mayor de San Marcos. 63 p.

22. Vadillo S, Píriz S, Mateos E. 2002. Géneros Nocardia, Rhodococcus, Dermatophilus, Streptomyces, Actinomyces, Actinobaculum y Arcanobacterium En: Manual de microbiología veterinaria. $2^{\mathrm{a}}$ ed. Madrid: McGraw-Hill Interamericana. p 327-338. 